\section{US urged to centralise scientific assessment of cancer risks}

A SINGLE scientific organisation responsible for identifying and characterising potential carcinogens across a range of government agencies has been recommended in a report prepared by the staff of the US Office of Science and Technology Policy.

Such an organisation, which it is suggested should be based on an expansion of the national toxicology programme established last year by the Department of Health, Education and Welfare, would have two main responsibilities: to identify those substances which pose a potential carcinogenic risk to humans, and to characterise in quantitative terms the nature of the risk and the degree of certainty of current estimates.

The report is part of an attempt by the administration to improve the scientific base of the regulatory process, a need which President Carter was expected to refer to briefly in a speech on regulatory principles which he was due to give this week.

Addressing a senate subcommittee last week, Dr Frank Press, the President's science adviser, said that one of the current needs in science policy was to carry out an analysis of the research base of the regulatory agencies to see if it was adequate. "If more resources are needed, I cannot think of a higher priority area than this one," he said.

Responding to a number of recent issues, such as heated debates over occupational exposure levels for lead and air pollution standards, the OSTP report says that in order to help develop a uniform decision-making framework for controlling potential chemical carcinogens, it is necessary to start by distinguishing scientific from regulatory decisions.

The first stage would involve scientific data collection and analysis, with risks expressed in comparative and quantitative terms, while the second would reflect a complete cost benefit analysis, taking into consideration human, economic and social factorsincluding the societal distribution on benefits and costs.

Priority for scientific analysis should be given to chemicals for which costbenefit analysis performed with existing data suggests that regulation be indicated, but leaves too much uncertainty to justify immediate action.

"Priority setting and coordination of testing ideally should be done by a single group with input from all relevant agencies," says the report, recommending this approach in contrast to one in which assessment would be assigned to various scientific organisations on an agency-by-agency basis. $\square$

\title{
UK ministry gives green light to 2,4,5-T
}

A REVIEw of the herbicide 2,4,5-T was published by the Ministry of Agriculture, Fisheries and Food (MAFF) last week. The document compiled by the Ministry's advisory committee on pesticides outlined the reasons for the MAFF announcement in July 1978 that herbicides containing $2,4,5-\mathrm{T}$ were safe "if used in the recommended way for the recommended purposes" and that approval had been given for their continued use in the UK.

This is the advisory committee's 8th review of 2,4,5-T since 1967 and it points out that the decision it reached was based on certain premises. These are that "in general the dose makes the poison", that there can never be "total proof of safety", that where reasonable doubt about the risk of a product exists the advisory committee's policy is to "err on the side of safety".

The review points out that it is the presence of the toxic contaminant 2,3,7,8-tetrachlorodibenzo-p-dioxin (dioxin)-a known teratogen and carcinogen-which is central to the concern over the safety of 2,4,5-T, some 3 tons of which are used annually in the UK-1/15 of the 1970 figure. Pure 2,4,5-T, the advisory committee

\section{MRC unit finds UK suicide rate falls}

THE MRC Clinical Psychiatry Unit in Chichester has released the results of a major study showing that from 19621974 suicide rates in the UK have declined in all age groups except young women of age 15-24. Cautioning against simple interpretations, Jim Jenkins, co-author of the report said that an "entire constellation" of factors must be taken into account in the case of the female figures including family size, number of children and patterns of female employment.

The overall decline in suicide rate could be attributed to the increasing social cohesion in Great Britain in the face of a declining standard of living and increasing unemployment. Ironically, the MRC unit itself is slated for unemployment. Following the Medical Research Council's usual policy of closing units when their directors retire the Chichester Unit will be closed in 1982.

An MRC site visit three years ago found that "suicide research had no future" and a petition to the MRC with the support of the MRC's National Staff Side Committee failed to re-open the case. "We tried to get the MRC to look at their decision again," says Jenkins, "but we were given no scientific explanation why the unit should be closed."

\section{Misha Voikhanskii finally permitted to leave Leningrad}

concludes, offers no hazard to users. And it adds that the dioxin itself would "ensure no hazard" if it was present in the trichlorophenol used to manufacture $2,4,5-\mathrm{T}$ in quantities less than $0.1 \mathrm{ppm}$.

In arriving at its conclusions, the committee reviewed several major studies on the herbicide, including a New Zealand Department of Health Safety Report which could find no link between human birth defects and 2,4,5-T spraying; an Australian National Health and Medical Research Council report refuting that birth defects in the state of Queensland were associated with the presence of dioxin caused by burning sugar cane stubble sprayed with $2,4,5-\mathrm{T}$; a West German Federal Health Office statement and Review each approving the use of the herbicide in the Federal Republic; and reports from Vietnam that 2,4,5-T spraying caused an increase in the incidence of malformation in children, but which were inconclusive owing to the inevitable inadequacy of the data from a war zone.

The advisory committee points out, however, that decisions such as this one on 2,4,5-T are never final.
Dr Marina Voikhanskaya, the former Leningrad psychiatrist, was forced to emigrate from the Soviet Union in 1975 after she had repeatedly refused to administer neuroleptic drugs to political "patients". Her nine-year-old son, Misha was to have followed her, but his promised emigration visa was withheld until a few days ago.

Since coming to the UK in 1975 , Dr Voikhanskaya has been an active campaigner against political misuse of psychiatry in the USSR. In 1977 she addressed the Honolulu meeting of the World Psychiatric Association on this subject. Meanwhile as Misha grew up he too became interested in psychiatric abuse. In December 1976, it was he who notified campaigners abroad that activist Vladimir Borisov had been taken to a psychiatric hospital.

Dr Voikhanskaya told Nature this weck that she felt sure that the long delay in Misha's visa was an act of reprisal against her for having spoken out against Soviet abuses of psychiatry. "It is only due to constant pressure from the scientific community and the public at large that the Soviet authorities have finally given way." 